\title{
Fewer Trichomonas vaginalis organisms in vaginas of infected women during menstruation
}

\author{
P DEMEŠ, * A GOMBOŠOVÁ,* M VALENT, ${ }^{*}$ H FABUŠOVÁ, $†$ A JÁNOŠKA $\dagger$ \\ From the *Institute of Parasitology and $\dagger$ Department of Dermatovenereology, Comenius University, Bratislava, \\ Czechoslovakia
}

SUMMARY The aims of the present study were to count Trichomonas vaginalis organisms recovered from the vaginas of patients with trichomoniasis, and to obtain data concerning changes in sizes of trichomonal populations during the menstrual cycle. In about $80 \%$ of symptomatic as well as symptomless patients, more than $1 \times 10^{5}$ parasites per $\mathrm{ml}$ could be obtained from vaginal washes. During menstruation, however, the number of trichomonads decreased appreciably, with subsequent increases within three to six days after bleeding.

The results indicated that sufficient numbers of fresh trichomonads may be obtained from vaginal washes for biochemical and molecular experiments and also confirm the previously reported trichomonocidal effect of menstrual blood complement in vivo.

The vaginal mucosa of healthy fertile women undergo profound changes during the menstrual cycle. ${ }^{12}$ Similarly, alterations in the quantity and composition of the mucus layer, which protects the vaginal wall from invasion, occur at various phases of the cycle. ${ }^{34}$ Changes in the vaginal microflora that accompany these shifts in the urogenital environment have also been reported. ${ }^{5-7}$

A complete alteration of vaginal milieu is brought about by menstrual bleeding. The micro-organisms in the vagina have to adapt themselves to different nutritional sources as well as to certain immune factors present in menstrual blood, but not in mucus. As yet only little attention has been paid to both the composition of menstrual blood ${ }^{8}$ and its relation to the vaginal flora. ${ }^{9}$

We studied the interaction of vaginal fluids with the protozoan parasite of the human urogenital system, Trichomonas vaginalis. We have shown that some menstrual blood sera can destroy the parasite in vitro and the role of complement in this process. ${ }^{10}$

The aim of the present study was to investigate the influence of menstruation on the density of $T$ vaginalis populations in the vaginas of patients with trichomoniasis.

Address for reprints: Dr Pavol Demeš, Departmemt of Pathology, University of South Alabama, 2451 Fillingim Street, Mobile, Alabama 36617, USA

Accepted for publication 19 May 1987

\section{Patients and methods}

\section{PATIENTS}

We studied 103 women (aged 16 to 56) attending the Department of Dermatovenereology and the Institute of Parasitology in Bratislava infected with $T$ vaginalis. Diagnosis was made by cultivation of trichomonads from vaginal swabs in Diamond's TYM (trypticase, yeast extract, and maltose) medium. " Clinical features of patients with trichomoniasis ranged from total absence of any signs or symptoms to inflammation of the mucosa. Abundant discharge or vulvovaginal irritation, or both, were the most common complaints of the symptomatic patients. All but 10 women (two pregnant, two having had hysterectomies, and six postmenopausal) were menstruating regularly.

\section{ISOLATION OF PARASITES}

$T$ vaginalis isolates were obtained by washing the posterior fornix of the vagina of infected women with $10 \mathrm{ml}$ sterile isotonic saline, which was instilled from and immediately aspired back to a syringe attached to a polyethylene tube. Single specimens were obtained from 15 women during menstruation and from 48 while they were not menstruating. Two successive isolates, one taken during menstruation and one extramenstrually, were collected from 24 patients who had had no sexual contact during the study. Three consecutive isolates, one taken during menstruation, were collected from nine women. The phase of the 
Table 1 Numbers of Trichomonas vaginalis organisms in vaginal washes from 63 patients with trichomoniasis

\begin{tabular}{lll}
\hline $\begin{array}{l}\text { Density of } \\
\text { parasites } \\
\left(\times 10^{5} / \mathrm{ml}\right)\end{array}$ & $\begin{array}{l}\text { No (\%) of women } \\
\text { menstruating } \\
(n=15)\end{array}$ & $\begin{array}{l}\text { No (\%) of women } \\
\text { not menstruating } \\
(n=48)\end{array}$ \\
\hline $0 *$ & $3(20)$ & 0 \\
$0 \cdot 1-1 \cdot 0$ & $9(60)$ & $7(15)$ \\
$1 \cdot 1-10 \cdot 0$ & $2(13)$ & $36(75)$ \\
$\geqq 10 \cdot 1$ & $1(7)$ & $5(10)$ \\
\hline
\end{tabular}

${ }^{*} T$ vaginalis cultivated after 48 hours.

menstrual cycle or day of menstrual bleeding was recorded for most of the patients.

The samples were assayed immediately for the density of trichomonads by counting motile parasites in a haemocytometer. Fresh isolates were cryopreserved in Diamond's TYM medium supplemented with 5\% dimethylsulphoxide either immediately after isolation or after subsequent axenisation as described elsewhere. ${ }^{12}$

\section{Results}

Table 1 shows the numbers of organisms recovered from patients during menstruation as well as from women in different phases of the cycle. During menstruation fewer than $1 \times 10^{5}$ trichomonads per $\mathrm{ml}$ wash were found in most (12/15) of the women. Outside menstruation the converse was true; a concentration of parasites of more than $1 \times 10^{5} / \mathrm{ml}$ was present in 41 of the 48 infected women. Mean concentrations of parasites were $1.8 \times 10^{5} / \mathrm{ml}$ in menstruating and $5.5 \times 10^{5} / \mathrm{ml}$ in non-menstruating women. The numbers of parasites in amenorrhoeic women equalled the densities in extramenstrual washes. We
Table 2 Influence of menstrual bleeding on vaginal populations of Trichomonas vaginalis in 30 patients with trichomoniasis

\begin{tabular}{lc}
$\begin{array}{l}\text { Changes in numbers of } \\
\text { trichomonads in vaginal washes } \\
\text { during menstruation* }\end{array}$ & $\begin{array}{l}\text { No (\%) of } \\
\text { women } \\
(n=30)\end{array}$ \\
\hline No change & $5(17)$ \\
$\begin{array}{l}\text { Decreased numbers } \\
\text { Increased numbers }\end{array}$ & $21(70)$ \\
& $4(13)$
\end{tabular}

*Compared with washes obtained at different phases of menstrual cycle from the same woman.

found no direct correlation between the number of $T$ vaginalis organisms and clinical features throughout the study.

Considering the complexity and variability of factors influencing the vaginal environment, we next studied changes in the trichomonad population during the menstrual cycles of 30 women. Vaginal washes were obtained during and before or after menstruation. In 21 of the 30 patients concentrations of parasites were reduced appreciably (mean $68.2 \%$, range $7-100 \%$ ) during menstruation compared with extramenstrually (table 2). The reduction in concentrations of the parasites was most distinct in the first two days of bleeding. During the last days of menstruation and immediately afterwards we observed an abrupt increase in numbers of parasites (figure).

\section{Discussion}

Local mucosal immune mechanisms, specific and nonspecific, provide the first barrier against most microbial invaders. ${ }^{1314}$ The participation of functional complement, an important humoral component of

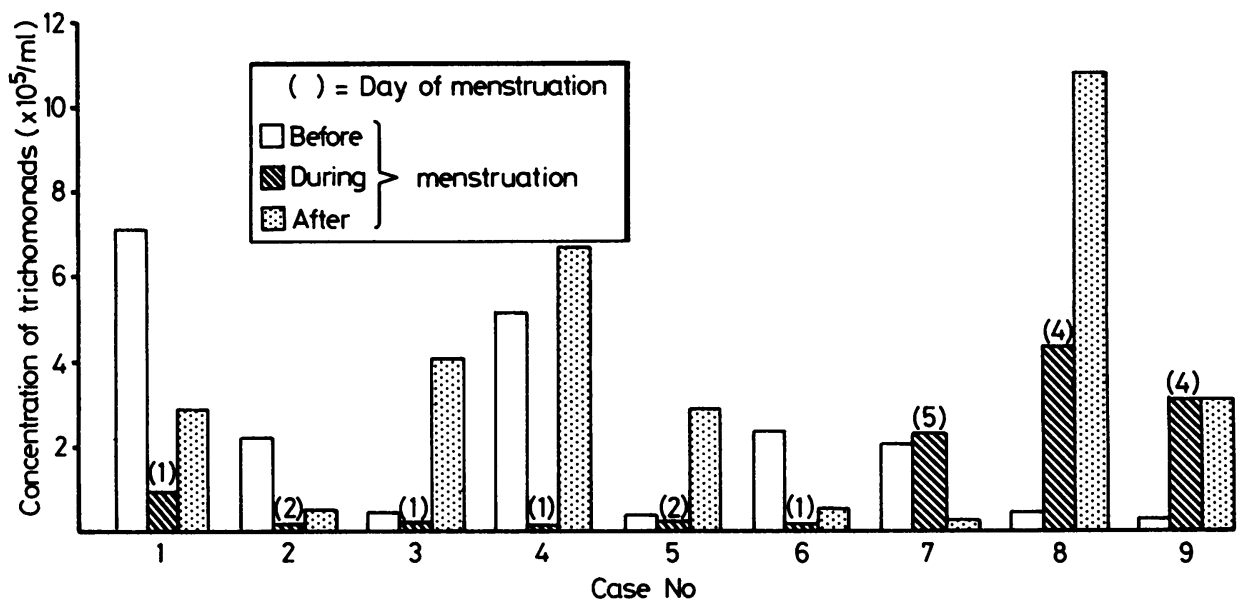

Figure Changes in concentrations of Trichomonas vaginalis organisms in vaginal washes from nine women with trichomoniasis 20 to nine days before menstruation, during menstruation (number indicates day of bleeding), and three to six days after menstruation. 
venous blood, in the protective effect of mucosal secretions, however, has not been satisfactorily shown until recently. ${ }^{315}$

Data from our previous study suggest that the human vaginal mucosa are in contact with haemolytic complement, at least during menstruation..$^{10}$ Menstrual blood of most women examined had a strong cytolytic effect in vitro on the vaginal pathogen, $T$ vaginalis, by a complement dependent mechanism.

In the present report, the data concerning the dynamics of trichomonad populations in the vagina were obtained from vaginal washes taken during and outside menstruation. The sampling procedure used in this study did not appreciably influence the parasite counts in subsequent washes. Such dramatic drops in trichomonad populations as are shown in the figure (case nos 1, 2, 4, and 6) were not observed in repeated (up to four times in a cycle) sampling outside menstruation (unpublished data). Thus the figure and tables 1 and 2 clearly show appreciable reductions in the concentrations of the parasite in the vaginas of most infected women during menstruation. A similar phenomenon in experimentally infected rhesus monkeys was described by Johnson et al. ${ }^{16}$ Though complement induced lysis is considered to be the mechanism responsible for lower parasite numbers, the participation of additional non-complement factors in some menstrual sera as well as the possible phagocytic activity of polymorphonuclear leucocytes ${ }^{17}$ of menstrual blood cannot be excluded.

Survival of $T$ vaginalis in the vagina during menstrual bleeding may be explained by the existence of subpopulations of trichomonads that are resistant to complement lysis. ${ }^{10}$ In this regard, other possibilities, such as the concentration of complement components or recolonisation of the vagina from the alternative sites of infection, have to be taken in account.

The resistance of trichomonads to immune mechanisms during menstruation appears to be an important factor in the maintenance of infection. A more detailed study of both complement and non-complement immune factors in menstrual blood and their association with vaginal pathogens is therefore essential for our understanding of relevant immune processes in the vagina.

We thank Mrs M Cerveńová and Miss J Ondzíková for their excellent technical help, and Miss $\mathrm{Z}$ Bínková for typing the manuscript.
References

1 Moghissi KS. Vaginal fluid constituents. In: Beller FK, Schumacher GFB, eds. The biology of the fuids of the female genital tract. New York: Elsevier, 1979:13-23.

2 Wied GL, Christiansen W. Bedeutung und Einfluss der Bakterienflora im zytologischen Vaginalausstrich. Zentralbl Bakteriol 1954;160:413-22.

3 Schumacher GFB. Humoral immune factors in the female reproductive tract and their changes during the cycle. In: Dhindsa A, Schumacher GFB, eds. Immunological aspects of infertility and fertility regulation. New York: Elsevier, 1980: 93-141.

4 Fleetwood L, Landgren BM, Eneroth P. Changes in protein soluble proteins in cervical mucus during midcycle in normally menstruating women. Gynecol Obstet Invest 1984;18:27-33.

5 Kurnatowska A. On the quantitative changes of Trichomonas vaginalis Donne in the course of menstrual cycles. Wiad Parazytol 1958;4:549-51 (Polish with English summary) and Ginekol Pol 29:139-50.

6 Landgren BM, Ljung-Wadstrom A, Wikborn C, Eneroth P, Nord CE. Microbial findings in genital secretions from seven healthy fertile couples. Med Microbiol Immunol (Berl) 1984;173:17985.

7 Johnson SR, Petzold CR, Galask RP. Qualitative and quantitative changes of the vaginal microbial flora during the menstrual cycle. Am J Reprod Immunol Microbiol 1985;9:1-5.

8 Beller FK, Schweppe KW. Review on the biology of menstrual blood. In: Beller FK, Schumacher GFB, eds. The biology of the fuids of the female genital tract. New York: Elsevier, 1979:231245.

9 Bartlett JG, Onderdonk AB, Drude E. Quantitative bacteriology of the vaginal flora. $J$ Infect Dis 1977;136:271-7.

10 Demeš $P$, Gombošová $A$, Valent $M$, Petrenko $M$, Jánoška $A$, Fabušová $\mathrm{H}$. Differential susceptibility of fresh Trichomonas vaginalis isolates to complement in menstrual blood and cervical mucus. Genitourin Med (in press).

11 Diamond LS. The establishment of various trichomonads of animals and man in axenic cultures. $J$ Parasitol 1957;43:488-90.

12 Gombošová A, Demeš $P$, Valent $M$. Immunotherapeutic effect of the lactobacillus vaccine, SolcoTrichovac, in trichomoniasis is not mediated by antibodies cross reacting with Trichomonas vaginalis. Genitourin Med 1986;62:107-10.

13 Hanson LA, Andersson B, Carlsson B, et al. Defence of mucous membranes by antibodies, receptor analogues and non-specific host factors. Infection 1984;12:111-5.

14 Allardyce RA, Bienenstock J. The mucosal immune system in health and disease, with an emphasis on parasitic infection. Bull WHO 1984;62:7-25.

15 Tauber PF, Wettich W, Nohlen M, Zaneveld LJD. Diffusable proteins of the mucosa of the human cervix, uterus and fallopian tubes: distribution and variations during the menstrual cycle. Am J Obstet Gynecol 1985;151:1115-25.

16 Johnson G, Kupfenberg AB, Hartman CG, Raritan NJ. Cyclic changes in vaginal populations of experimentally induced Trichomonas vaginalis infection in Rhesus monkeys. Am J Obstet Gynecol 1950;59:689-92.

17 Rein MF, Sullivan JA, Mandell GL. Trichomonacidal activity of human polymorphonuclear neutrophils: killing by disruption and fragmentation. $J$ Infect Dis 1980;142:575-85. 